\title{
KINETICS AND MECHANISM OF THE PHOTOCHROMISM OF N-PHENYL-RHODAMINELACTAME
}

\author{
H. WILLWOHL and J. WOLFRUM \\ Physikalisch-Chemisches Institut, Im Neuenheimer Feld 253, \\ D-6900, Heidelberg \\ R. GLEITER \\ Organisch-Chemisches Institut, Im Neuenheimer Feld 270, D-6900, \\ Heidelberg
}

(Received 12 April, 1988; in final form 7 July, 1988)

\begin{abstract}
The photochromism of $\mathrm{N}$-phenyl-rhodaminelactame $\left(3^{\prime}, 6^{\prime}\right.$-bis-(diethylamino)-2-phenyl-spiro[ $1 \mathrm{H}$ isoindole-1, $9^{\prime}[9 \mathrm{H}]$ xanthen]-3-[2H]-one) was investigated in solutions of acetonitrile, dioxane and mixtures of dioxane with $\mathrm{H}_{2} \mathrm{O}$, methanol and ethanol by laser flash time resolved absorption measurements. The colouring reaction kinetics and the relative quantum yield of the red product were measured using nanosecond excimer laser excitation at $308 \mathrm{~nm}$. In most cases, first order kinetics was observed. The first order rate constants and the quantum yield were found to be dependent on the solvent and the number of laser pulses that had previously irradiated the solution. The thermal fading reaction occurred on a millisecond timescale and showed large deviations from first order kinetics in all solvents. In addition, picosecond laser pulses at $285 \mathrm{~nm}$ were used to measure the fluorescence lifetime of the $\mathrm{S}_{1}$ state of the rhodamine derivative with picosecond resolution. Single exponential decays were observed in all solvents and the lifetime ranged between 3 and 6 nanoseconds. We conclude that the photoreaction does not proceed directly from the $S_{1}$ state, and propose a mechanism for the photochromic process, in which an intermediate decomposes to rotameric isomers of the coloured product, which are not equilibrated on the millisecond time scale of the reverse reaction.
\end{abstract}

KEY WORDS: Photochromism, rhodamine derivative, photokinetics, laser excitation.

\section{INTRODUCTION}

Since the first studies on photochromism of organic molecules ${ }^{1}$ a wide variety of compounds have been investigated in this area because of their possible applications in optical switches and optical storage devices. ${ }^{2}$ The most important groups of compounds are the spiropyrans, ${ }^{3,4}$ triarylmethanes, ${ }^{5}$ polymethincolours, ${ }^{6}$ and substances that show $e-z$ isomerization of double bonds. ${ }^{7}$ In most of these systems the photochromic process proceeds by photochemically induced heterolytic bond fissure to a normally coloured zwitterionic structure followed by thermally induced reformation of this bond back to a colourless form of the molecule. Some rhodamine derivatives are known to exhibit photochromism through this mechanism. ${ }^{8}$

Mechanism 1.gives the simplest form for the photochromic process for the title compound. 


\section{MECHANISM 1}<smiles>CCN(CC)c1ccc2c(c1)Oc1cc(N(CC)CC)ccc1C21c2ccccc2C(=O)N1c1ccccc1</smiles>

$\underline{1}$

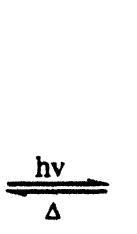<smiles>CCN(CC)c1ccc2c(c1)Oc1cc(N(CC)CC)ccc1C21c2ccccc2NC(=O)c2ccccc21</smiles>

2

In this work we tested if this simple mechanism can explain the photochromic behaviour of this compound by investigating the influence of solvents and irradiation time on the relative quantum yield and reaction rate. We propose a more detailed mechanism of the photochromic process unifying microsecond absorption measurements and picosecond fluorescence measurements.

\section{EXPERIMENTAL}

The rhodamine derivative was synthesized as described previously. ${ }^{9}$ All solvents used were spectral grade and used without further purification. Typical concentrations employed were $9 \times 10^{-5} \mathrm{~mol} / \mathrm{l}$. During each experiment the solutions were degassed by bubbling nitrogen. In some experiments oxygen was used to aid in elucidating the presence of triplet excited transients. Absorption spectra were recorded on a Perkin Elmer Lambda 7 UV/VIS spectrophotometer. The laser flash experiments were carried out with a Lambda EMG MSC $201 \mathrm{XeCl}$ excimer laser ( $25 \mathrm{~ns}$ pulsewidth at $308 \mathrm{~nm}$ ). The laser beam was focussed by a cylindrical lens into a rectangular quartz cell with $2 \mathrm{~mm}$ pathlength along the excitation axis. The energy absorbed by the sample was determined by measuring the beam energy in front of and behind the quartz cell with a Gentec ED 500 joulemeter. The whole content of the cell was irradiated by the laser beam which is assumed to have a nearly homogeneous profile. The absorbed energies were in the range of $20-40 \mathrm{~mJ}$.

Reference light was produced by a continuously operating Oriel $150 \mathrm{~W}$ Xenon arc lamp. The pathlength of reference light through the sample cell was $10 \mathrm{~mm}$. Behind the quartz cell the reference light was focussed onto the slit of a Zeiss MQ 3 monochromator.

The selected probe wavelength was in the region of 550-555 $\mathrm{nm}$ (see Figure 1). An EMI 6256 A photomultiplier installed at the exit slit of the monochromator recorded the light intensity. The resulting signal was measured by a Tektronix $7623 \mathrm{~A}$ oscilloscope and stored on the screen (100 ns time resolution). Kinetic data was 
obtained by photographing the trace and fitting the curve to the standard kinetic equations.

Fluorescence measurements with picosecond time resolution were carried out on a system described in detail elsewhere. ${ }^{10.11}$ Therefore only a brief description is presented here. A distributed feedback dye laser $(285 \mathrm{~nm}$ wavelength, $10 \mathrm{ps}$ pulsewidth, $50 \mu \mathrm{j}$ energy) was used for excitation of the sample. The fluorescence signal was detected by a streak camera (Hamamatsu C 1537) in the range of 400-500 nm (maximum of fluorescence emission) perpendicular to the excitation beam (40 ps time resolution).

\section{EXPERIMENTAL RESULTS}

Figure 1 presents the UV spectra of the coloured and uncoloured forms of the rhodamine derivative in acetonitrile. The colourless form shows a strong absorbance peak at $314 \mathrm{~nm}(\log \epsilon=4.11$ for the fresh solution) which decreases slightly afer each illumination cycle. The spectrum of the coloured form was obtained by illuminating the fresh solution with 50 laser pulses $(308 \mathrm{~nm}, 150 \mathrm{~mJ}, 50 \mathrm{~Hz})$ and subsequently recording the UV/VIS absorbance. The'so obtained spectrum shows an absorption at $555 \mathrm{~nm}$ due to a $n-\pi^{*}$ transition in the zwitterion (see mechanism 1). The extinction coefficient of this peak cannot be calculated, because the absolute concentration of the coloured form is not known. The spectra of the two forms in the other investigated solvents show only small shifts of the absorbance peaks from Figure 1.

Irradiation experiments were performed at $308 \mathrm{~nm}(25 \mathrm{~ns}, 150 \mathrm{~mJ})$ in acetonitrile,

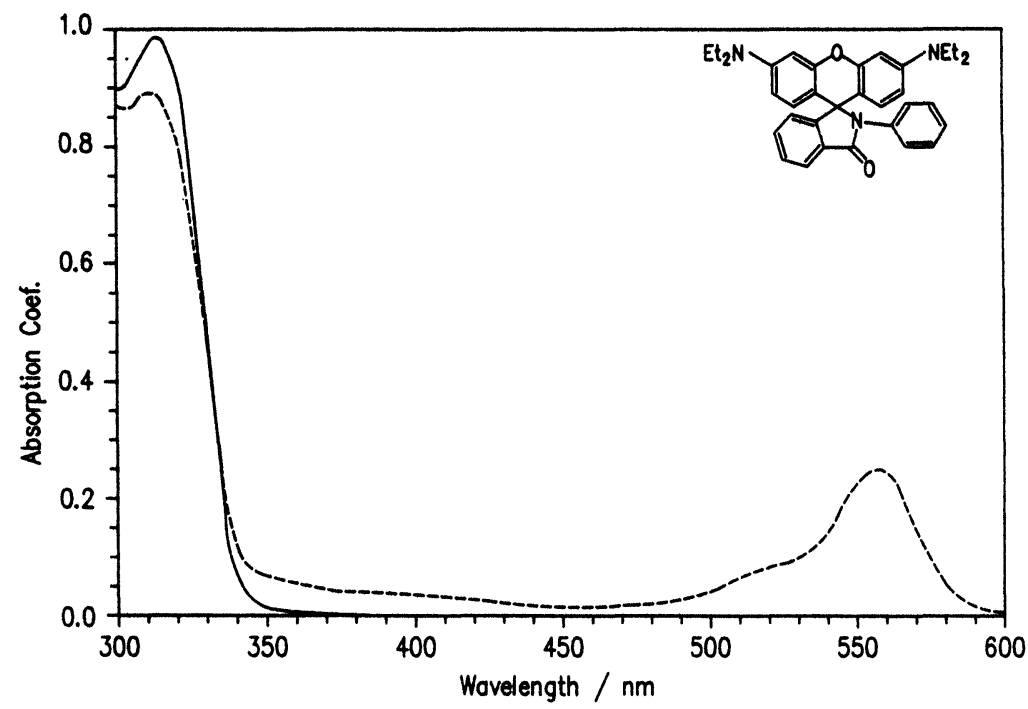

Figure 1 UV spectra of $\mathrm{N}$-phenyl-rhodaminelactame: —unirradiated form. $\left(\lambda_{\max }=314 \mathrm{~nm} \log \epsilon=\right.$ $4.11), \ldots$ irradiated form $\left(\lambda_{\max }=555 \mathrm{~nm}\right)$ in acetonitrile. 
dioxane and mixtures of dioxane with ethanol, methanol and water. We used mixtures of solvents because the solubility of the derivative in pure $\mathrm{EtOH}, \mathrm{MeOH}$ and $\mathrm{H}_{2} \mathrm{O}$ is not high enough to study the photocolouration reaction with the equipment used here.

\section{Photocolouration Reaction}

After excitation the rise of the absorption signal at $550 \mathrm{~nm}$ occurs on a timescale of $\mu \mathrm{s}$. Figure 2 shows some of the recorded plots for the time behaviour of the absorption at $550 \mathrm{~nm}$ in different solvents. The kinetic behaviour is clearly first order for every solvent used except dioxane (not shown in Figure 2). The relative quantum efficiency of the photoreaction in each solvent was determined by comparing the absorption signals in each system. The quantum efficiency and the kinetics of the colouring reaction in all investigated solvents were found to be dependent on the number of laser pulses that had irradiated the solution before the analyzed exciting pulse. The rate constants for the appearance of the coloured form are summarized in Table 1 and range from $0.7 \times 10^{4} \mathrm{~s}^{-1}$ in dioxane/EtOH to $4 \times 10^{5} \mathrm{~s}^{-1}$ in dioxane/ $\mathrm{MeOH}$. With increasing number of laser pulses the reaction rate increases (see Figure 2). Figure 3 shows the relative quantum efficiency of the colouring reaction as a function of the number of laser pulses before the analyzed pulse in dioxane/ $\mathrm{MeOH}=10 / 1$, dioxane $/ \mathrm{EtOH}$ and dioxane $/ \mathrm{H}_{2} \mathrm{O}$. The quantum efficiency of the colouring reaction after the first exciting pulse was in all cases too small to allow a kinetic evaluation of the data. After a number of reaction cycles the quantum efficiency reaches a maximum, after which the yield of coloured product for each cycle decreases due to irreversible side reactions leading to fatigue of the photochromic system. The behaviour in the other investigated systems was similar. Results obtained in oxygen saturated solutions were not significantly different from those obtained with nitrogen.

\section{Thermal Fading Reaction}

The kinetics of the thermal fading reaction was studied at room temperature $\left(22^{\circ} \mathrm{C}\right)$ by time resolved detection of the decrease of the $550 \mathrm{~nm}$ absorbance band, which occurred on a timescale of $\mathrm{ms}$ in all investigated solvents, except acetonitrile

Table 1 Rate constants of the colouring reaction. Ranges do not reflect experimental uncertainty but rather the number of previous laser shots (see text)

\begin{tabular}{lll}
\hline Solvent & $\begin{array}{l}\text { Composition } \\
\text { (volume ratios) }\end{array}$ & $k_{1}\left(\times 10^{4} \mathrm{~s}^{-1}\right)$ \\
\hline Dioxane $/ \mathrm{H}_{2} \mathrm{O}$ & $10 / 1$ & $2.3-4$ \\
Dioxane $/ \mathrm{EtOH}$ & $10 / 1$ & $0.7-1$ \\
Dioxane $/ \mathrm{MeOH}$ & $10 / 1$ & $1-8$ \\
Dioxane $/ \mathrm{MeOH}$ & $20 / 1$ & $16-40$ \\
\hline
\end{tabular}




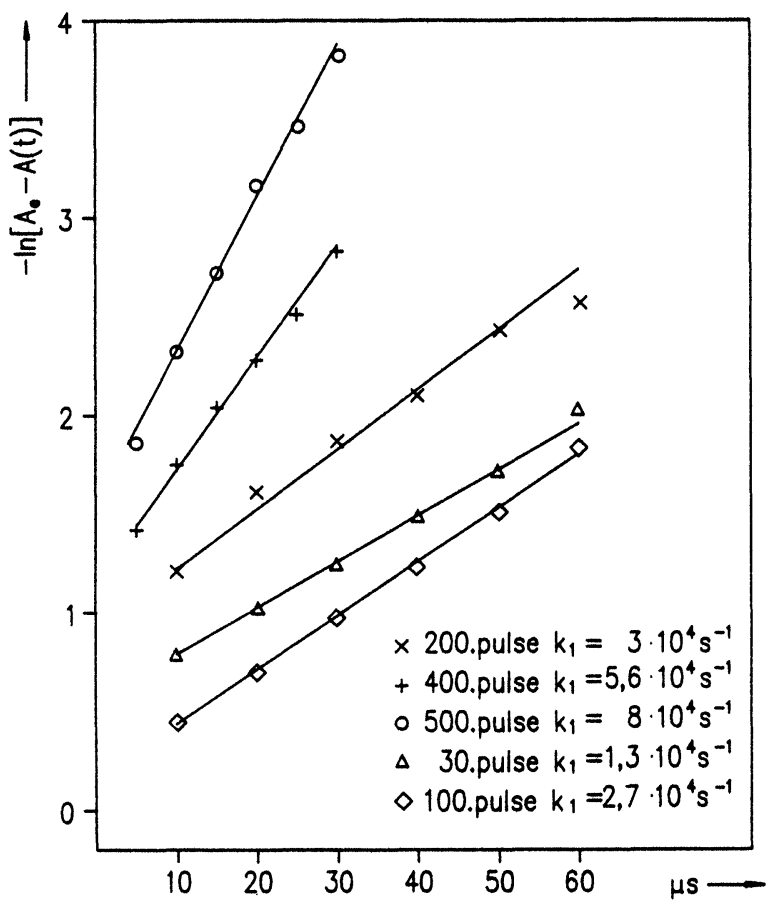

(a)

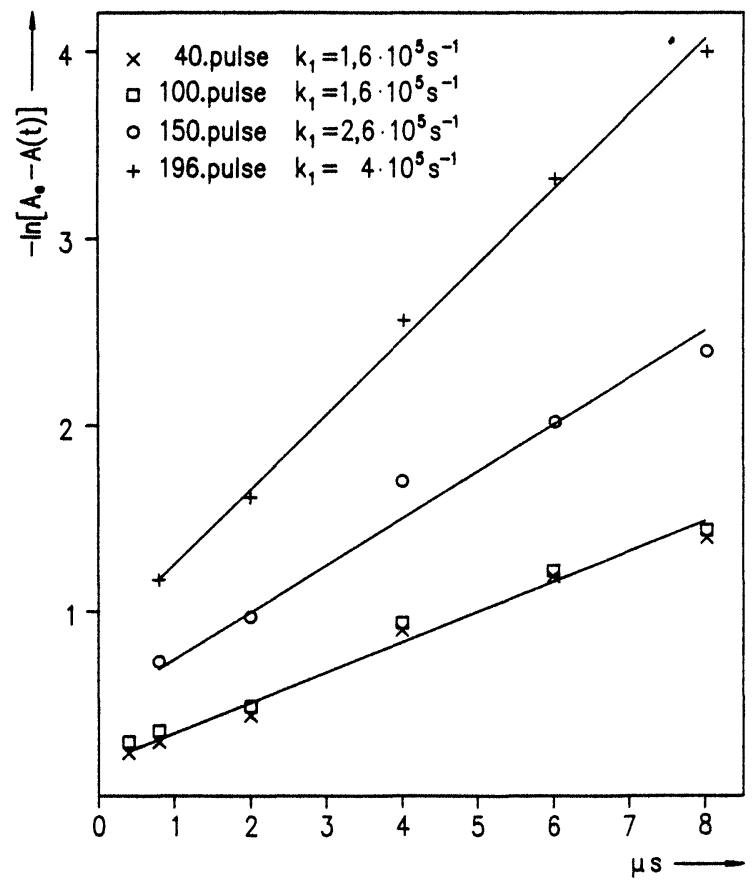

(b)

Figure 2 First order kinetic behaviour of the absorption signal at $550 \mathrm{~nm}$ after repeated laser pulses at $308 \mathrm{~nm}:(\mathrm{a})(\triangle, \diamond)$ in dioxane $/ \mathrm{H}_{2} \mathrm{O}=10 / 1,(\times,+, \mathrm{O})$ in dioxane/ $\mathrm{MeOH}=10 / 1$. (b) In dioxane/MeOH $=$ $20 / 1$. 


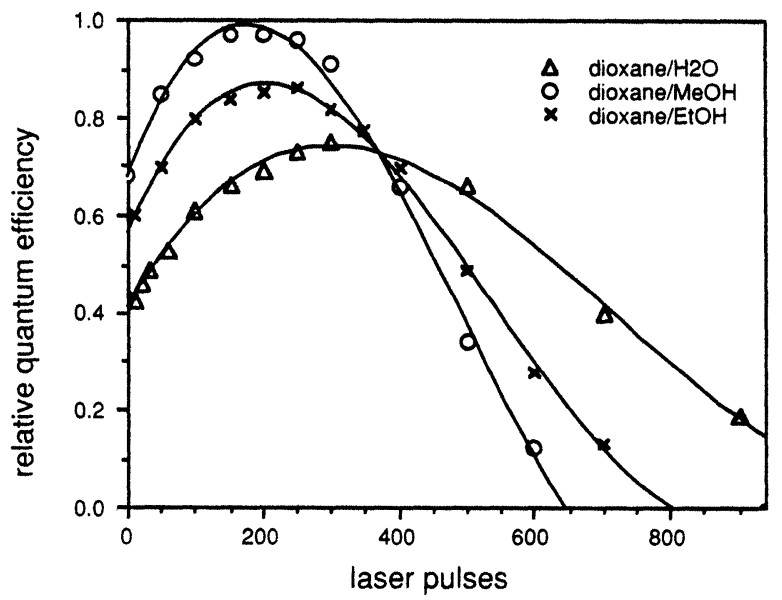

Figure 3 Relative quantum efficiencies of the colouring reaction as a function of numbers of laser pulses in dioxane $/ \mathrm{H}_{2} \mathrm{O}(\Delta)$, dioxane $/ \mathrm{MeOH}=10 / 1(0)$, dioxane/EtOH $(\times)$.

(timescale of $\mathrm{s}^{8}$ ). In none of the investigated cases was the temporal behaviour first order as shown by the curves in Figure 4. Table 2 presents the half reaction times of the fading reaction in each of the investigated solvents. The fading reaction rate was strongly solvent dependent (in dioxane/ $\mathrm{MeOH} 20$ times faster than in dioxane/ $\mathrm{EtOH}$ ). In contrast to the colouring reaction the rate of the fading reaction decreased with increasing number of laser pulses.

Table 2 Half reaction times of the thermal fading reaction

\begin{tabular}{lll}
\hline Solvent & $\begin{array}{l}\text { Composition } \\
\text { (volume ratios) }\end{array}$ & $\tau(\mathrm{ms})$ \\
\hline Dioxane & - & 200 \\
Dioxane $/ \mathrm{H}_{2} \mathrm{O}$ & $10 / 1$ & $60-200$ \\
Dioxane $/ \mathrm{EtOH}$ & $10 / 1$ & $50-400$ \\
Dioxane $/ \mathrm{MeOH}$ & $10 / 1$ & $20-30$ \\
Dioxane $/ \mathrm{MeOH}$ & $20 / 1$ & $40-100$ \\
\hline
\end{tabular}

\section{Fluorescence Lifetime Measurements}

Figure 5 shows the decay of the fluorescence intensity in dioxane. In the observed time range of $6.5 \mathrm{~ns}$ the decay appears to be single exponential. The radiative lifetime of the singlet state $\left(S_{1}\right)$ of the derivative was determined to be $4.4 \mathrm{~ns}$. Comparison of the fluorescence spectra of the fresh solutions with the preirradiated ones did not show any differences in lifetime. In all other investigated solvents the lifetime was in the region of 3-6 ns. 


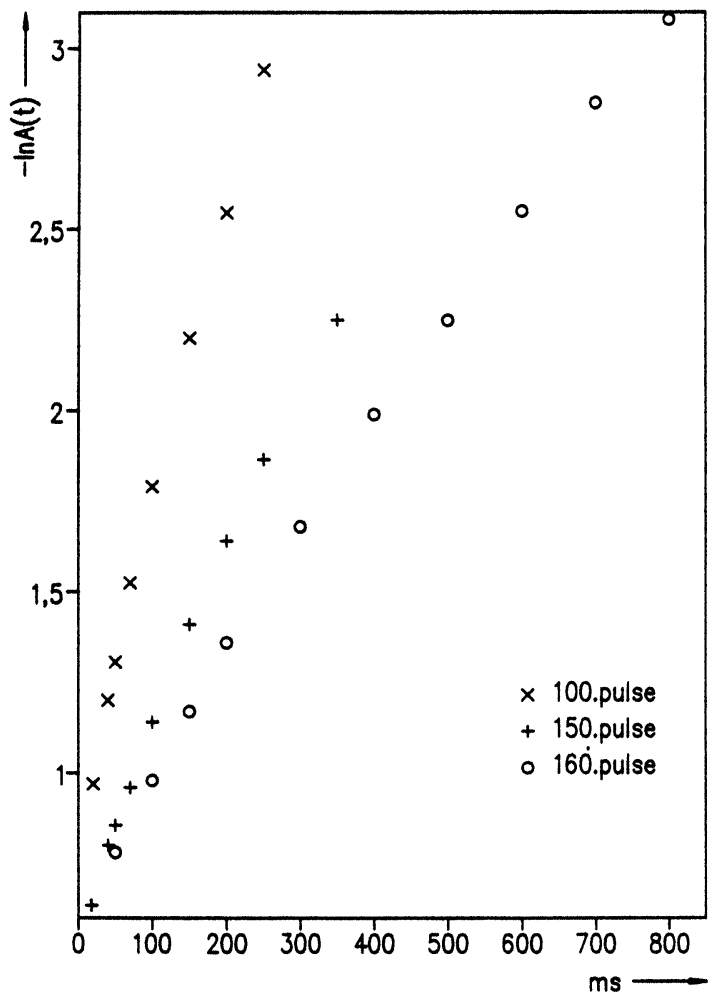

(a)

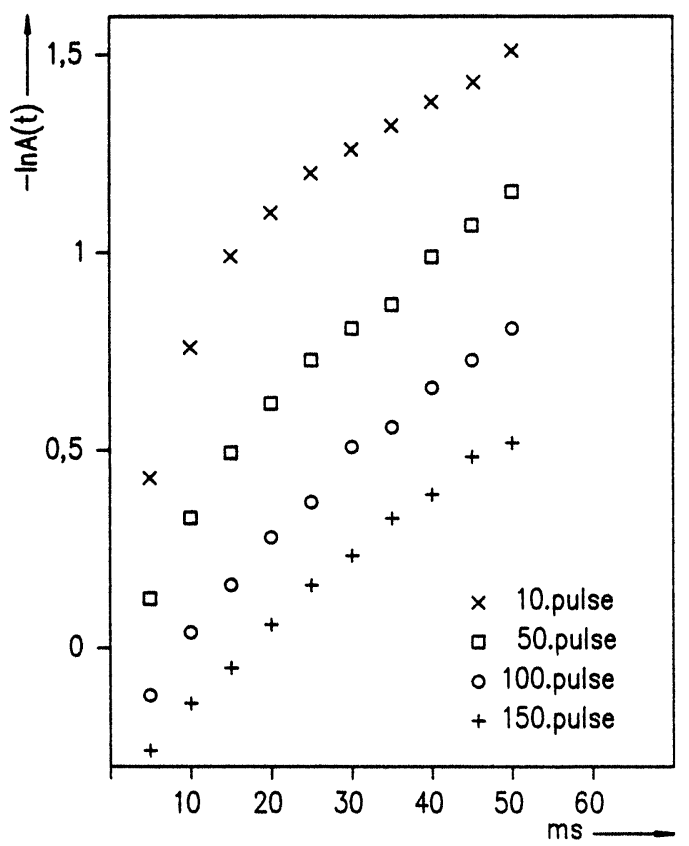

(b)

Figure 4 Kinetic behaviour at $550 \mathrm{~nm}$ for the thermal fading reaction. (a) In dioxane/ $\mathrm{H}_{2} \mathrm{O}=10 / 1$. (b) In dioxane $/ \mathrm{MeOH}=10 / 1$. Non first order behaviour in all cases. 


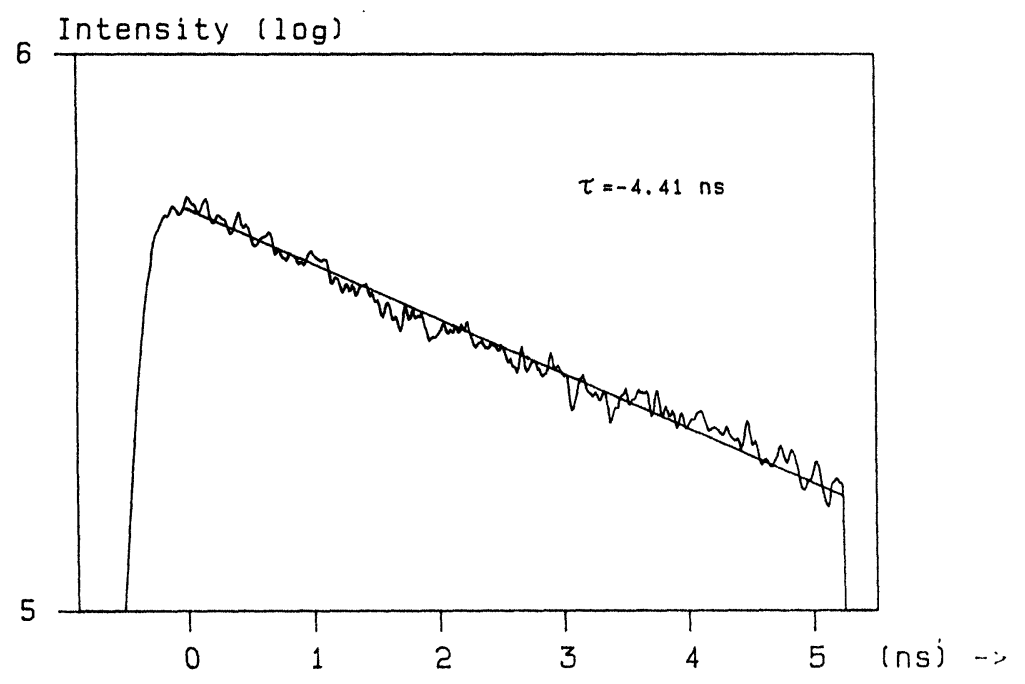

Figure 5 Single exponential fluorescence decay of $\mathrm{N}$-phenyl-rhodaminelactame in dioxane. The radiative lifetime of the singlet state $\left(\mathrm{S}_{1}\right)$ is $4.4 \mathrm{~ns}$.

\section{DISCUSSION}

From our experimental results we conclude that mechanism 1 does not completely describe the photochromic reaction system, because it can explain neither the deviations from first order kinetics in the fading reaction nor the dependence of the rate constants and the relative quantum efficiency for the appearance of the coloured product on the number of irradiating laser pulses.

From the experimental data we deduced a reaction sequence more complete than that in mechanism 1.

From the deviation of the fading reaction from first order kinetics we conclude that there are at least two coloured forms; these are likely to be the rotameres 2a and $\mathbf{2 b}$ of the zwitterionic form (see Figure 6). Increasing quantum efficiency and reaction rate for the photochemical induced reaction can be explained by two reactant molecules. At the beginning of the reaction cycle the solution contains only the colourless form $\mathbf{1}$. By irradiation we produce the two coloured forms $\mathbf{2 a}, \mathbf{b}$ which may decay into reactant 1 again or into the new lactonic form 3 (see Figure 6). This new colourless form has a higher relative quantum efficiency and reaction rate for the colouring reaction than form 1 . This result is plausible because $\mathrm{C}-\mathrm{O}$ bonds (form 3 ) are generally weaker than $\mathrm{C}-\mathrm{N}$ bonds (form $\mathbf{1}$ ) and it explains the slight changes in the UV spectra of the colourless forms after each reaction cycle. In addition the reaction sequence must involve an intermediate because the lifetime of the singlet state $\left(S_{1}\right)$ is in the order of 3-6ns but the coloured product appears only after some $\mu \mathrm{s}$. This intermediate $\mathbf{X}_{\mathbf{a}}$ for reactant $\mathbf{1}, \mathbf{X}_{\mathbf{b}}$ for reactant $\mathbf{3}$ ) is probably not the triplet state in contrast to results obtained with $6^{\prime}$-nitroindolinospiropyran ${ }^{12}$ ), because of the 

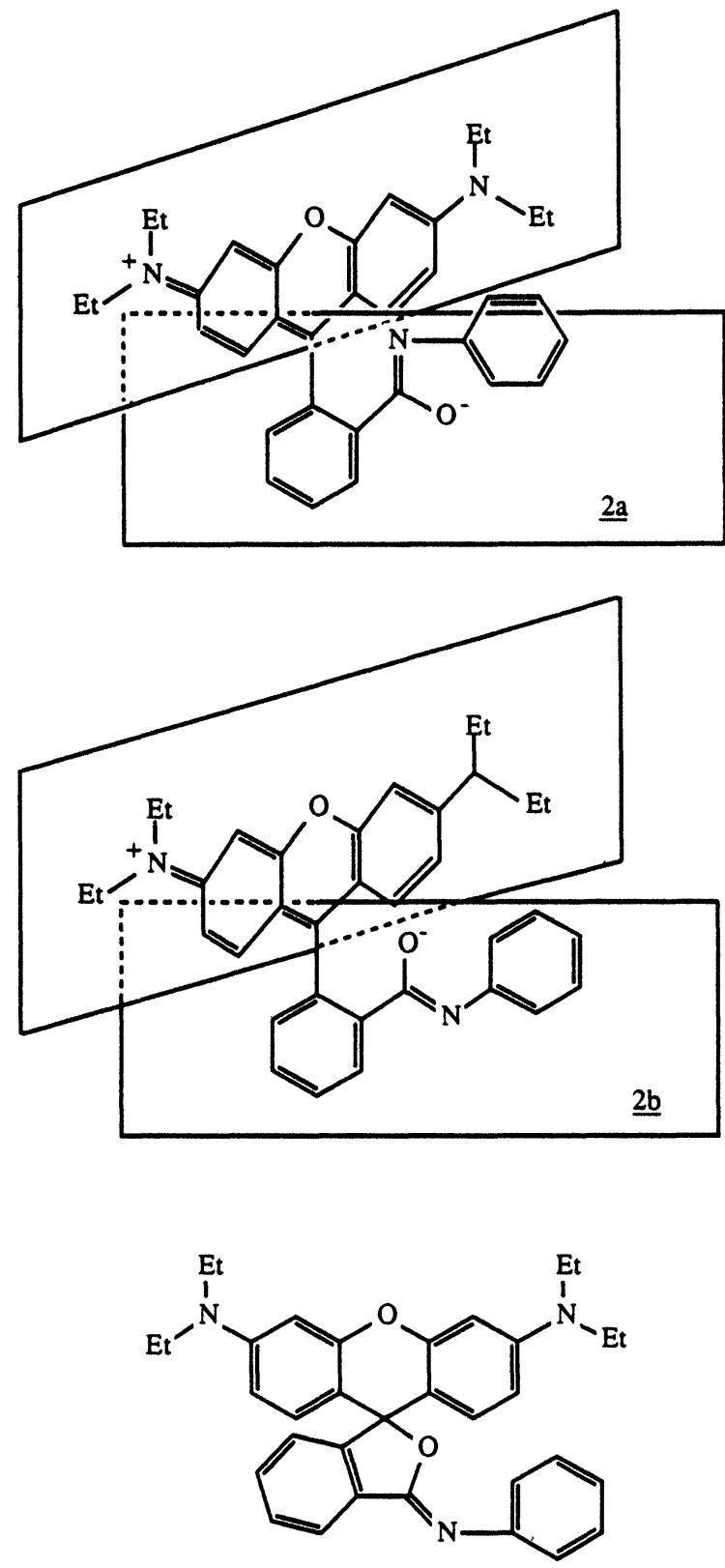

Figure 6 Structures of the two proposed coloured forms $2 a, 2 b$ in mechanism 2, both containing as chromophore a pyronine system (pyronine $B$ : $\lambda_{\max }=553 \mathrm{~nm}$ ) and structure of the lactonic form 3 . 


\section{MECHANISM 2}

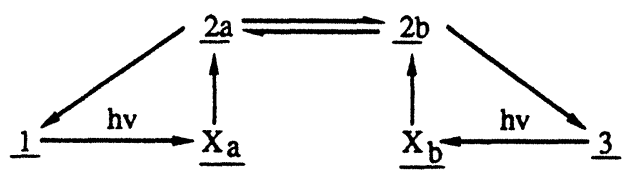

lack of an $\mathrm{O}_{2}$ effect on the quantum efficiency of the reaction. Unfortunately, attempts to look for an intermediate by absorption measurements between $300 \mathrm{~nm}$ and $600 \mathrm{~nm}$ were unsuccessful. To proof mechanism 2 it is important to detect 3 but detection of $\mathbf{3}$ in the presence of $\mathbf{1}$ may be difficult since we expect their UV, IR and NMR spectra to be very similar.

\section{Acknowledgement}

The authors gratefully acknowledge the Forschungsschwerpunkt 35 Baden-Württemberg for the generous financial support and Dr. J. W. Ager for his help in revising the manuscript.

\section{References}

1. G. H. Brown, Techniques of Chemistry, Vol. III, Photochromism (Wiley-Interscience, New York, 1971).

2. S. Reich, Angew. Chem. 89, 467 (1977).

3. E. Fischer, Chemie in unserer Zeit 9, 85 (1975).

4. T. Bercovici, R. Heiligman-Rim and E. Fischer, Mol. Photochem. 1, 23 (1969).

5. Kito, Nakasiju, Kaoka and Inagaki, Ger. Offen. 3, 213 (1984).

6. A. Hantzsch and G. Osswald, Chem. Ber. 33, 306 (1900).

7. E. Fischer, Fortschr. Chem. Forsch. 7, 605 (1967).

8. K. H. Knauer and R. Gleiter, Angew Chem. 89, 116 (1977).

9. S. Dutt and J. E. Thorpe, J. Chem. Soc. 125, 2524 (1924).

10. R. Schwarzwald, P. Monkhouse and J. Wolfrum, Chem. Phys. Lett. 142, 15 (1987).

11. R. Schwarzwald and O. Greulich, Ber. Bunsenges. 92, 447 (1988).

12. C. Lenoble and R. S. Becker, J. Phys. Chem. 90, 62 (1986). 